\title{
Collaborative Systems in Support of Reindustrialization
}

\author{
Luis M. Camarinha-Matos \\ FCT - Universidade Nova de Lisboa and Uninova, Campus de Caparica \\ 2829-516 Monte Caparica, Portugal \\ cameuninova.pt
}

\begin{abstract}
The establishment of collaborative business ecosystems is widely accepted as a key strategy in the reindustrialization processes. This is clearly present in the ongoing policy discussions and industry-oriented research roadmaps. A brief analysis of recent contributions to the PRO-VE conference shows the active role already played by the collaborative networks community in this process. Focusing on areas such as service orientation and serviceenhanced products, sustainability issues, collaboration stimulation strategies, co-innovation, and improvement of distributed processes, the area is contributing with valuable models, organizational structures, infrastructures and tools to enable a new generation of sustainable industrial systems.
\end{abstract}

Keywords: Reindustrialization, Collaborative Networks, Sustainability.

\section{Introduction}

The term reindustrialization has appeared to represent the economic, social, and political process of organizing resources for the purpose of re-establishing / revitalizing industries in order to reinvigorate the economy. After decades of industrial decline, due to deliberate policies that advocated an exclusive move towards a service-oriented society, while neglecting the production of tradable goods, many countries are struggling with hard public and private belt-tightening measures which only accelerate the crisis spiral. While the urgent need for growth and job creation are getting attention in the policy agendas, technical discussions more and more focus on new approaches for manufacturing, value creation, operational excellence in distributed contexts, agility, and collaborative networks.

Sustainability issues, considering the three pillars of environment protection, economic growth, and social progress, are clearly upfront in these trends. Any effective solution in the direction of sustainable industrial approaches imposes collaboration of multiple stakeholders organized in mixes of dynamic value chain networks. New collaborative systems need to be developed under a well-integrated socio-technical perspective.

This introductory chapter intends to briefly highlight the relevant contribution that collaborative networks can have in the development of a new generation of industrial systems able to address major societal challenges. For this purpose, a brief analysis of relevant literature and research roadmaps is made. 


\section{Some Literature Trends}

The first wave of literature on reindustrialization appeared in the 1980s, particularly in Europe and the USA. In the case of Europe, most discussions were associated to the political changes in Central and East Europe and were focusing on the creation of new, innovative industries, activities and products, with high priority for environmental protection industry [1]. The transformation processes were associated to the crisis and decline of state-owned industries, leading to some de-industrialization [2]. By the same time, considerable discussions on reindustrialization, productivity, and competitiveness were also taking place in the USA [3], [4]. The need for collaborative strategies among various stakeholders for effective reversal of stagnant or declining economies was already recognized in this period [5].

More recently, in the sequel of the ongoing economic crisis, the subject became again on top of the political agenda. For instance, a manifesto for growth and employment in Europe [6] advocates the need:

"To organize technological and industrial cooperation in all sectors and all regions: building new industries, European players of international dimensions, and creating ecosystems for innovation and investment call for sustainable partnerships".

The Foundation Robert Schuman also points out the importance of cluster networks in the strategy to reduce disparities between regions and overcoming innovation gaps [7]. At the European Commission level it is particularly relevant the new target for 2020 to counter the decline of Europe's industrial base and increase the share of manufacturing in EU's GDP to 20\% [8], [9]. Many discussions around reindustrialization and economic revitalization appear associated to transformations along the lines of a green economy.

A recent manufacturing outlook report by KPMG [10] also highlights the importance of collaboration:

"While the lean manufacturing revolution was focused on getting businesses' own houses in order, the challenge now is to improve supply chain performance through genuinely closer working relationships and collaboration across the network".

Improved end-to-end visibility of the supply chain is also pointed out as key for optimization, which is synonymous of more effective collaboration. ICT collaboration platforms and tools are fundamental enablers in this process. According to the same report [10], when asked "what are the major challenges your company faces in its ability to innovate?", manufacturing companies identified top 5 challenges:

1. Aligning innovation to company strategy;

2. Complexities in collaborating with suppliers and partners;

3. Executing innovation - on time and on budget;

4. Shortage of ideas to drive innovation;

5. Incomplete view of / difficulty understanding the needs of customers.

Besides the second challenge, which clearly requires collaborative networks contribution, also concepts such as co-innovation, open innovation, or glocal enterprise, which are addressed in current research by the collaborative networks community, can bring significant inputs to challenges 4 and 5 . 


\section{Industry-Oriented Research Roadmaps}

Realizing the importance of manufacturing in "growth and jobs", a prerequisite for societal sustainability, EFFRA has elaborated a multiannual roadmap [11] with research and innovation priorities for Factories of the Future under the Horizon 2020 program of the European Commission. The roadmap is designed with the aim of having a significant impact in the following major long-term objectives:

- Maintain and create new jobs in manufacturing.

- Increase value added by manufacturing.

- Address environmental concerns, by reducing emission of gases, energy consumption, waste generation, and consumption of materials.

- Enhance attractiveness of jobs in manufacturing.

- Increase the number of manufacturing enterprises engaged in innovation and R\&D.

The roadmap identifies 6 main research and innovation priorities (Fig. 1). When observing the details of each priority and the proposed research actions, the role of collaborative networks becomes evident. This role is most obvious in the priority "Collaborative and mobile enterprise", in which the proposed actions are clearly aligned with research topics in collaborative networks. But relevant contributions of collaborative networks and collaborative systems are also identifiable in all the other priority domains, as summarized in Fig. 1.

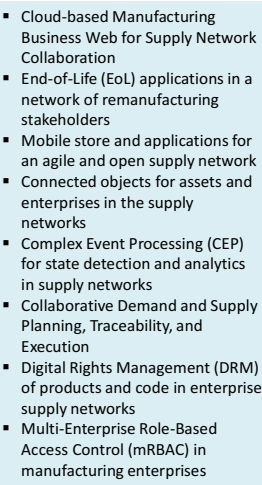

- Digital Rights Management (DRM) of products and code in enterprise supply networks

Multi-Enterprise Role-Based

Access Control (mRBAC) in

manufacturing enterprises

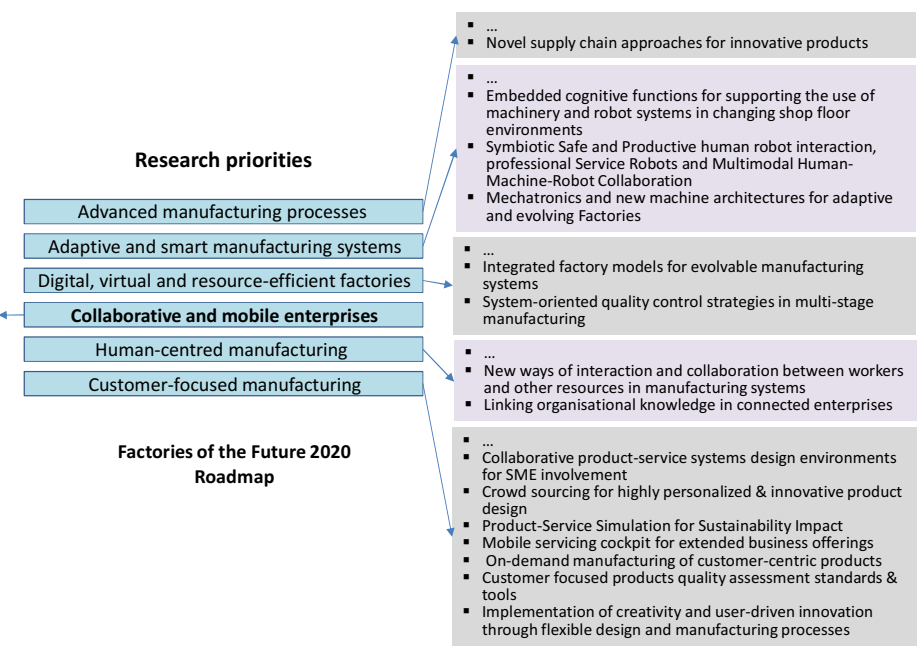

Fig. 1. Role of collaborative systems in the FoF 2020 roadmap

A complementary roadmapping initiative is represented by the position paper towards Horizon 2020, elaborated by the FInES (Future Internet Enterprise Systems) cluster [12]. This document is organized around 5 research priorities aimed at supporting Internet-based disruptive enterprise innovation towards competitive advantage development and sustainable growth. 
As illustrated in Fig. 2, in all these priority areas collaborative networks is a major contributing discipline.
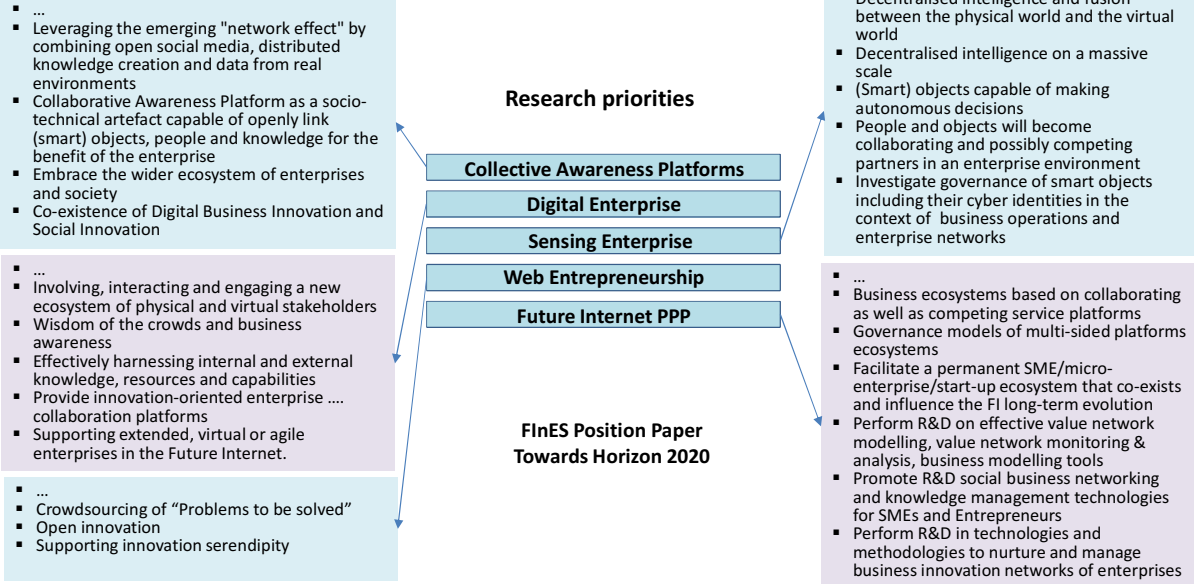

Fig. 2. Role of collaborative systems in the FInES position paper towards Horizon 2020

\section{Examples of Contributions from Collaborative Networks}

The 2013 edition of PRO-VE was specifically focused on the contribution of collaborative systems for reindustrialization and, as such, it presents a good overview of current contributions [13]. Furthermore, many other important contributions can also be found in other recent editions, with particular relevance to the ones devoted to sustainability [14], value creation [15], and Internet of services [16].

Fig. 3 gives an overview of the main areas covered by the selected papers. It shall be noted that some papers address more than one area.

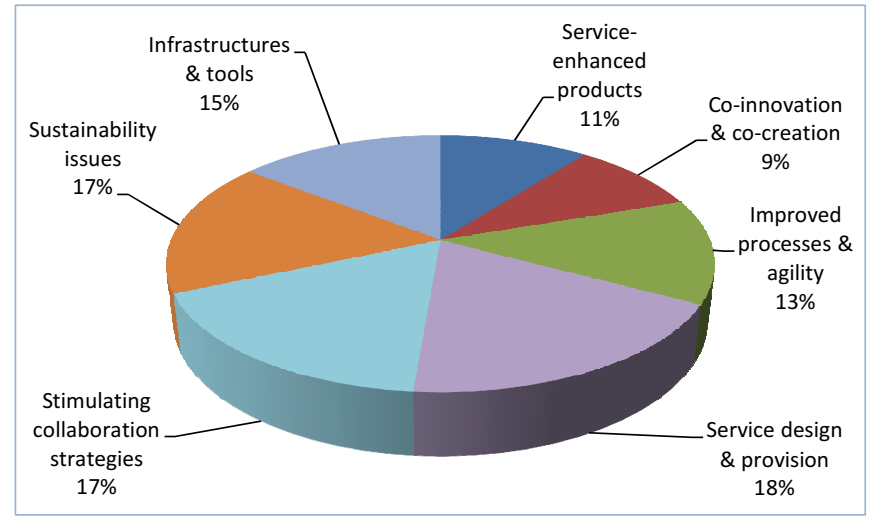

Fig. 3. Main covered areas in PRO-VE'13 
Focusing on Service-Enhanced Products. The notion of service-enhanced product, also known as product-service, represents the association of business services to the physical product, adding value to the product along its life-cycle through better satisfaction of customer needs. The term product-service system (PSS) is also used, including the product, the associated services, the involved enterprises network, and the needed infrastructure. Examples of significant research topics under this item:

- Notion of "servitization" and "service-dominant strategy" to represent a mindset shift from goods-dominant logic to service-dominant logic;

- Role of service enhancement in sustainability and methods to assess that sustainability;

- Organization of collaborative ecosystems to provide the services, introducing the perspectives of multi-stakeholders collaborative value creation and cocreation through the involvement of the customer;

- Identification and characterization of the interplay among various collaborative networks along the product life-cycle such as product manufacturing network, service co-creation network, product servicing network, and the long-term ecosystem or manufacturers VBE;

- The notion of glocal enterprise in the product-enhanced services, highlighting the role of the customer and its related "community" (local suppliers, regulators, other local stakeholders) and the interplay of this "community" with the manufacturers network;

- Understanding and modeling the contribution of the various stakeholders in value proposition to form a PSS;

- Identification of critical decision processes and decision centers in the transition to PSS;

- Specification and configuration of customized complex products;

- Assessment of (industrial) service procurement processes;

- Value systems alignment in the creation of product servicing networks;

- Cloud-based collaboration platforms and tools to support service-enhanced product ecosystems.

Focusing on Co-innovation. The notion of co-innovation refers to a collaborative process involving not only industry stakeholders but also the customer in the design of new solutions. Examples of relevant research topics include:

- Strategies and mechanisms to promote the creation of innovation networks;

- Key roles and processes in co-creation of intellectual property;

- Service co-creation networks and processes;

- Mechanisms to assess knowledge circulation in co-innovation networks;

- Co-creation support platforms and collaboration spaces.

Improving Processes and Agility. Various research activities continue focused on the improvement of distributed business processes, redesign of processes towards more optimized operation, and configuration and reconfiguration of networks. Examples include:

- Incentives, sanction mechanisms, and fair distribution of benefits;

- Transportation logistics optimization; 
- Sensor networks in large-scale monitoring;

- Collaborative cyber-physical systems in process monitoring;

- Identification and characterization of collaborative processes;

- Context-aware process modeling methods;

- Representation of behavior related processes;

- Consortia formation and reconfiguration of collaborative networks to support better coordination and control.

Focusing on Service Design and Provision. The growing importance of (business) services and the need to better "engineer" them led to the emergence of new research streams such as services science and services design. Services science is a movement trying to clarify the notion of service in all its dimensions and provide a sound conceptual framework for the area. Service design aims at providing effective approaches and tools for service design, addressing the functionality and form of the services. In particular, it aims to ensure that service interfaces are useful, usable, and desirable from the client's perspective, while being also effective, efficient, and distinctive from the supplier's perspective. Examples of relevant research topics:

- Modeling services life-cycle;

- Methods for services discovery and selection based on non-functional properties:

- Role of mobile and location-based services in dynamic value chains;

- Dynamic negotiation and contracting of services to support agile manufacturing networks;

- Handling uncertainties associated with partnerships in provision of sustainable services, e.g. dealing with variability of governance structures, climate of relationships, behavioral uncertainty, performance variations, etc.;

- Methods to support service co-design, with particular focus on visual thinking approaches;

- Cost prediction for service systems, namely in co-creation contexts;

- Approaches to "industrialize" the service design and service innovation processes;

- Interaction patterns in NFC interfaces for services;

- Service level agreements in cloud-based environments;

- Adaptation of service design tools to different industries;

- Identification and characterization of services in fashionable products;

- Development of energy-control services for smart homes based on multistakeholders collaboration;

- Collaboration in effective service recovery in incidents management.

Stimulating Collaborative Strategies. A substantial group of diversified contributions are focusing on strategic and managerial approaches to promote collaboration. Examples of addressed topics include:

- Trends in global economy and facilitators for intercontinental collaboration;

- Dynamic networks and employment structure;

- Approaches to enhance collaboration strategies and anything relationships management;

- Legal and regulatory frameworks to promote enterprise networks; 
- Collaborative approaches in revitalizing rural communities;

- Promotion of public-private collaboration;

- Evolution of business models in networks;

- Collaboration forms in the tourism and healthcare sectors;

- Risk analysis and trust promotion methods;

- Exploiting the value of social networks, namely in terms of information fusion and knowledge extraction.

Addressing Sustainability in Its Various Perspectives. The role of collaborative networks in sustainability has deserved considerable attention in the last years [14] and is likely to continue a major topic of research. Examples of current issues include:

- Models to promote sustainable packaging and transportation logistics, aiming at reducing environmental impacts;

- Collaborative networks in reverse logistics and end-of-life manufacturing challenges;

- Enterprise networking in support of remanufacturing and recycling;

- Role of intangible assets in business sustainability;

- Power distribution and sustainability of the networks;

- Sustainability issues in networked mass customization, namely addressing variability rationalization.

Developing Infrastructures and Tools. In addition to the various technological components and systems included in previous sections, the developments of collaboration platforms and generic collaboration support tools offers important enablers for the actual establishment of collaborative networks. Examples of developments include:

- Collaboration spaces - models and support functionalities;

- Knowledge-based architectures to support co-creation;

- Collaboration platforms for learning environments;

- Cloud-based collaboration platforms;

- Collaborative planning support tools;

- Event-driven architectures and event marketplaces;

- Support for dynamic composition of processes.

The above examples do not constitute an exhaustive representation of research in this domain but provide a comprehensive set of examples of issues being tackled by a large variety of research groups [13], and which are likely to contribute to effective reindustrialization.

\section{$5 \quad$ Concluding Remarks}

The perspective of collaboration and enterprise networks has become a central issue in the ongoing policy agendas and initiatives to revitalize industry. As such, collaborative networks play a relevant enabling role in the reindustrialization processes. This is well recognized in recent literature and strategic research roadmaps for future manufacturing and enterprise systems. A survey of current research in the collaborative networks area, as represented by the contributions to recent PRO-VE conferences, illustrates well how collaborative systems and models are being developed and evaluated in support of a new industrial landscape. 
Acknowledgements. This work was funded in part by the European Commission through the GloNet project (FP7 programme).

\section{References}

1. Horváth, G.: Preliminary thoughts on the role of reindustrialisation and environmental protection in regional development. In: Baranyi, B., Fodor, I. (eds.) The Role of Environmental Industry in the Regional Reindustrialization in Hungary, pp. 9-18. Hungarian Academy of Sciences, Centre for Regional Studies (2009)

2. Lux, G.: The re-emerging role of industry in Central European economies. In: Baranyi, B., Fodor, I. (eds.) The Role of Environmental Industry in the Regional Reindustrialization in Hungary, pp. 19-34. Hungarian Academy of Sciences, Centre for Regional Studies (2009)

3. Bachelor, L.: Reindustrialization in Detroit: Capital Mobility and Corporate Influence. Journal of Urban Affairs 4(3), 35-50 (summer 1982)

4. Norton, R.D.: Reindustrialization and Economic Development Strategy. Economic Development Quarterly 3(3), 188-202 (1989)

5. Beauregard, R.A., Lawless, P., Deitrick, S.: Ollaborative Strategies for Reindustrialization: Sheffield and Pittsburgh. Economic Development Quarterly 6, 418-430 (1992)

6. CE. Manifesto for growth and employment - Let's reindustrialize Europe. Confrontations Europe (2012), http: / /www. confrontations .org/images / confrontations / publications/Articles/Manifesto\%20-\%20EEE-of-Bologna.pdf

7. Lirzin, F., Schramm, C.: Reindustrialising Europe: the issues at stake in a European Innovation and Industrial Policy. Foundation Robert Schuman, European Issues $\mathrm{N}^{\circ} 256$ (October 23, 2012), http://www.robert-schuman.eu/en/doc/questionsd-europe/qe-256-en.pdf

8. ENDS. Commission launches re-industrialisation drive (2012),

http: / /www. fead.be/uploads /

ENDS\%20Europe\%20re-industrialisation.pdf

9. EC. Moving forward to an industrial renaissance to overcome economic crisis (2013), http: / /ec.europa.eu/enterprise/newsroom/cf /

itemdetail.cfm?item_id=6737\&lang=en

10. KPMG (2013). Global Manufacturing Outlook - Competitive advantage: enhancing supply chain networks for efficiency and innovation (May 2013)

11. EFFRA. Factories of the Future PPP - FoF 2020 Roadmap: Consultation document (2012), http: / / www.effra.eu/attachments/article/335/ FoFRoadmap2020_ConsultationDocument_120706_1.pdf

12. FInES. Embarking on New Research Orientations towards Horizon 2020, FInES Position Paper (2013), http://www. fines-cluster.eu/fines/jm/Front-PageNews / embarking-on-new-research-orientations-towards-horizon2020-a-fines-position-paper-in-the-works.html

13. Camarinha-Matos, L.M.: Collaborative systems in support of reindustrialization. In: Camarinha-Matos, L.M., Scherer, R.J. (eds.) PRO-VE 2013. IFIP AICT, vol. 408, pp. 3-10. Springer, Heidelberg (2013)

14. Camarinha-Matos, L.M., Boucher, X., Afsarmanesh, H. (eds.): PRO-VE 2010. IFIP AICT, vol. 336. Springer, Heidelberg (2010)

15. Camarinha-Matos, L.M., Pereira-Klen, A., Afsarmanesh, H. (eds.): PRO-VE 2011. IFIP AICT, vol. 362. Springer, Heidelberg (2011)

16. Camarinha-Matos, L.M., Xu, L., Afsarmanesh, H. (eds.): Collaborative Networks in the Internet of Services. IFIP AICT, vol. 380. Springer, Heidelberg (2012) 